\title{
Another Mishegas: Global Citizenship
}

\section{Michael Woolf}

CAPA International Education

In The New Joys of Yiddish, Leo Rosten defines mishegas as follows:

Mishegas: Literally: insanity, madness.

But mishegas is more often used in lighter vein to describe not mental disease but

- a wacky, irrational, absurd belief; nonsense; hallucinations. "Did you ever hear such a piece of mishegas?"

- a fixation, an idée fixe. "She has a new mishegas - that the neighbours are trying to ruin her."

- an idiosyncrasy $^{1}$

\section{Introduction: The Problem of Inflation}

The value of education abroad as part of undergraduate experience is real and, sometimes, measureable. Anecdotally at least, students frequently assert that they have matured, widened their horizons and gained insights into the world elsewhere. For many of us that is, quite simply, a given: an observable reality. Problems arise when the value of the enterprise is exaggerated to the point where unrealistic expectations are established and where the rhetoric is burdened by hyperbole. That kind of rhetoric masks and distorts tangible benefits that are far from being elusive.

The unfortunate consequence (usually a product of marketing zeal) is that the importance of raising international awareness gets buried in a morass of aspirational excess. Education abroad is not, for example, essential. Many millions of students in the world achieve significant levels of educational attainment without being able to afford to enhance their undergraduate experience abroad. Education abroad is a privilege enjoyed, even in the USA, by very few students; it is an irrelevance for many students around the globe (especially those in the developing world): an aspiration about as realistic as a desire to walk upon the moon. This kind of inflated rhetoric debases the serious purpose of education abroad which is to enhance the academic studies of those students who can afford to participate. 
The purpose of this essay is to focus on another of the assertions that have accumulated around the work of international education professionals and practitioners: the idea of the global citizen. The propagation of this notion derives from, essentially, two sources: it is a recurrent claim made by study abroad programs $^{2}$ and it is used also a means of self-description. The objective is to explore some of the assumptions behind the phrase which, ultimately, do a disservice to the credible aspirations embedded in international education. There is no intention to denigrate or criticise individuals who describe themselves as global citizens. The phrase when used in a personal context usually describes someone who is, or who aspires to be, broad minded, intellectually engaged with other cultures, aware of the interdependence of nations, committed to tolerance and understanding of difference, and so on. That describes, I will argue, a good citizen. Shared beliefs in international values impose no rights or legal obligations. It is a voluntary, ethical assertion not a form of membership which is one necessary component of citizenship. The global adjective is obfuscation (or, as Leo Rosten might say, a mishegas).

\section{Some of the Problems: what is the Globe? What is a Citizen?}

The notion of global citizenship assumes, firstly, that there is such an entity as the "globe" that exists in something more than a purely geographical sense. The second assumption is that it is possible to be a citizen of such a place (if indeed it existed). The key question in this context derives from the fact that, in the commonly understood sense, a citizen is a "member" of an entity with rights and duties that are legally guaranteed/required. How is it possible to be a citizen of something that has no legal existence and that exists (outside of geography) only as a metaphor?

There are, of course, legal and moral aspects to the notion of citizenship but, inherently, being a citizen is, in one way or another, belonging to a "club". You belong and others do not. Thus, in a geo-political sense a citizen is also defined by the excluded counterpart. Historically, this has had the consequence of encouraging conflict between cities or nations where the superiority of one set of citizens is asserted over another. In this perspective, global citizenship exists as a science fiction construct: the "other" is not part of this globe. We are in War of the Worlds territory where we assert our global citizenship as a communal response to assault from other planets.

If that is a little fanciful, the undeniable reality is that we tend to exaggerate the number of activities that are truly global. It is possible to argue that the conse- 
quences of events may well have a global dimension (economics, environmental matters). It is also clear that some ideas have (or have had) global aspirations. That would be true of the "grand narratives" whether religious or political (Communism, Catholicism, Fascism, Islam and so on). Nevertheless, these manifestations fall short of creating effective worldwide entities. In any case, those need to balanced against, and seen in the context of, nationalist policies that intend to restrict the impact of globalization, particularly those aimed at reducing international labor mobility, as April Carter argues:

The result of economic globalization is often economic and environmental exploitation. Freedom of movement around the world is largely confined to financial capital and to highly skilled professionals, whilst frontiers are closed to the poor and unskilled desperate for work-or they are allowed in as temporary labor, but denied any rights. ${ }^{3}$

The idea of a global citizen may, nevertheless, have a profound moral dimension and there is no disrespect intended towards that position. To achieve that meaning, however, it is necessary to create the kind of rhetorical slide achieved by Franklin Roosevelt. In this case, he speaks of the closely related notion of world citizenship:

We have learned that we cannot live alone, at peace, that our own wellbeing is dependent on the well-being of other nations, far away. We have learned that we must live as men, and not as ostriches, nor as dogs in the manger. We have learned to be citizens of the world, members of the human community. ${ }^{4}$

What Roosevelt does, of course, is to conflate the moral position and the legal position so as to give greater weight to his political commitment to engage with other nations (this was 1945 after all). The key is in the repetition of "learned" which, beneath the rhetoric, enforces the sense that this is a process not a condition: a consciousness gained by experience and reflection. It is not possible, outside of the world of wishful metaphor, to learn to be a citizen (you may learn to be a good citizen or, indeed, become a bad citizen but that is an adjectival qualification of a legal state or condition). You may certainly learn those things necessary to become a citizen but the movement from non-citizen to citizen is an event, not a process. 
The concept of the 'global citizen' is obviously an oxymoron-we are citizens of a country and we are not citizens of the globe: the "globe" is a very fractured and divided place. The problem is that, if we tell students that what we do is educate them to be global citizens by (for example) sending them to Paris for four weeks or even for a year, we are embedding failure into the experience by creating inflated claims for anticipated learning outcomes. Rather, we should be more realistic and say that the goal of study abroad is to create better educated citizens, and one of the ways to cultivate a better educated citizen is to experience another culture. The idea of cosmopolitanism is a far more realistic and manageable goal: the object is to teach students something about another culture so they can be better citizens of their own. This is not mere semantics but reflects the need to put education (rather than the rhetoric of transformation) at the centre of education abroad.

The status of a "global citizen" is an absolute condition (you either are or are not). In contrast the notion of cosmopolitanism is progressive. It is possible to be more or less cosmopolitan and it is, thus, a learning process, not some envisaged state of grace. Similarly, the ideas of cultural awareness or international consciousness, in contrast to the condition signified by global citizen, have within them the necessary sense of a progression (from less to more): something that can be learned and taught: the business of education.

The notion of a "global citizen" is, however, not without meaning. As a metaphor, it forefronts and prioritizes the cosmopolitan over the parochial. In that sense, it is aspirational; a moral rather than a legal condition that asserts the interdependence of humanity. The values associated with the phrase, repeatedly, stress such core ideas as empathy for others, a belief in common human rights, care for the environment and so on. An attempt to define global citizenship is made by Oxfam. The key characteristics are: awareness of the wider world, respect for diversity, outrage at social injustice, community engagement, and the desire to make the world a more sustainable place. These qualities are patently descriptive of a good citizen (a phrase that means something, albeit not exactly the same thing, everywhere) and are indicative of cosmopolitan values.5 Few of us would find anything to object to in these ethical positions. They define a moral human in a world more and more inter-connected at many levels. Nothing is gained by defining those values as, in some way or another, "global". They are, sadly, not globally shared. A key objective in education abroad is to raise the international consciousness of students so that they may become, progressively, better citizens. 
There is, in short, no definition of a global citizen that could not be applied to the notion of a good citizen: global here means good.

On the other hand, the idea of the global citizen may also signal the development of a new privileged and empowered class: those who have access to technology and travel are this new global elite. The gap between this stratum and the dispossessed is a chasm:

...there may emerge two tracks of citizenship: national and global, with the latter being more prestigious. Along with greater separation between rich and poor, educated and not, there would also be those relegated to living out their entire lives in one land, compared to those who freely travel to many. 6

This is an insight missing from Thomas Friedman's The World is Flat. Friedman argues that characteristic of what he calls "Globalization 3.0" "is the new found power of individuals to collaborate and compete globally". Technological advances have, according to Freedman, created a "flat-world platform":

And when it did, people all over the world started waking up and realizing that they had more power than ever to go global as individuals... every person now must, and can, ask: Where do I as an individual fit into the global competition and opportunities of the day, and how can I, on my own collaborate with others globally? 8

That notion flies in the face of reality. The United Nations High Commissioner for Refugees (UNHCR) has a category called "people of concern" which includes displaced persons, refugees, and others forced to leave their homes through upheavals and threats external to them. This group among many many others is not, it can be comfortably assumed, asking the question that Friedman sees as imperative. At the beginning of 2004, the estimated number of people in this category was around 19.5 million. By 2005 the figure had grown to around 21 million (about the same as the total population of Texas). That is 1 in 300 of the entire world's population. By 2006, the number had grown to an estimated 32.9 million (just below that of California). This is an enormous population that is involuntarily mobile; they are not, by any definition, global citizens or, indeed, in many cases citizens of anywhere at all. It is simply and literally not true to assert that "All humans possess equal worth without regard to nationality, ethnicity, or religion." ${ }^{9}$ We may argue that this should be true for all humans but that is a significantly different statement. It is about noble aspiration not current reality. 
There is no need to belabor this point. The gap between the privileged and the dispossessed grows wider. Participation in the globalization process and "the opportunities of the day" is limited to a global elite. We may define this global elite (which includes us) precisely by the fact that we have access to the money, technology and resources that empower us to become, in some metaphorical sense, global citizens.

The rhetoric of globalization also needs to be approached with particular skepticism in the context of information technology. The World Wide Web is by no means a global tool. Access remains limited predominantly to the developed world through the medium of English. It is also estimated that less than $50 \%$ of the world's population have made a telephone call ${ }^{10}$ let alone connected to the Web. $40 \%$ of the world's population does not have reliable electricity supplies. It takes a particular lack of vision to reach Friedman's conclusion in India (of all places) where the gap between the rich and the dispossessed is so clearly visible. Friedman is, of course, aware of the existence of what he calls "the unflat world". Beneath the troubled and awkward metaphor, Friedman is, in fact, describing a globalised class system. Furthermore, the world can hardly be described as flat when, by the author's admission, "a good proportion of it is unflat". The whole thing is a bit rocky, not to say bumpy i.e. not flat at all.

The notion of a globalised world is also problematic in that it signifies a very selective analysis of contemporary trends. While many activities become global in reach (from pop culture to drug smuggling) there is a simultaneous fragmentation of nations into sub-national (even tribal) groups, as Lagos argues:

Aninterestingparadoxofglobalizationiswhiletheworldisbeinginternationalized at the same time it's also beinglocalized. The world shrinks as the local community (village, town, city) takes on greater and greater importance. ${ }^{11}$

The use of the term global citizen needs, therefore, to be nuanced and not used as a glib and hyperbolic marketing claim in study abroad. It is a complex, contested proposition and not a condition to be achieved through the purchase of experience. On the one hand, it signals an aspirational, even utopian, view of the world. On the other, it identifies a powerful elite: a new emergent transnational upper class from which much of the world is significantly distanced, above all, through poverty.

Ahmed Samatar elegantly sidesteps the issue (with a subtle shift-note the use of "then") by using the terms cosmopolitanism and global citizenship interchangeably: 
I suggest, therefore, that "Global Citizenship," to respond effectively to both the ideational and concrete local and planetary challenges that may confront us, may include the following: an extension of selfhood to belong to the human race without foregoing more local or regional affinities. Cosmopolitanism, then, is a fusion of immediate and transnational conceptions of self-a gateway to the revival of inclusive empathy; an identification of the problematique at a given time; a discerning analysis; and a common praxis towards desirable and achievable utopia. ${ }^{12}$

In essence, underlying this argument is the notion of global citizenship as a form of rhetorical flourish. In contrast, cosmopolitanism leads more readily towards specificity.

Much the same strategy is found in J. Michael Adams and Angelo Carfagna's Coming of Age in a Globalized World: The Next Generation:

Cosmopolitanism literally means being a citizen of the world, and commonly includes or implies a global awareness or ethic. We use the term frequently in the following discussion as a synonym for world citizenship, although we understand that cosmopolitanism has often been used to describe elite circles of world travelers and consumers not exactly preoccupied with moral rights and responsibilities. For that reason, in other places, we prefer to use the term "world citizen" or "global citizen." 13

There are a number of matters arising here. Certainly, the terms world and global citizen are frequently used interchangeably, and there is no inherent issue in that. The issue arises with the word "citizen" in that, as previously noted, there is no progressive state possible. It is impossible to be a bit of a citizen.

Whatever the issues related to cosmopolitanism, it permits a progressive acquisition. It is possible to be more or less cosmopolitan and it is, therefore, far more accurate within the context of education which is, precisely, a process taking participants for one level of knowledge or awareness to another level. Distrust of the term derives, in part, from some stereotypical formulations and associations (some of them antiSemitic in origin) of cosmopolitanism with international rootlessness. ${ }^{14} \mathrm{~A}$ more neutral term might be international awareness but, without wanting to be bogged down in semantics, the key distinction for educators is simply, can be it be progressively acquired? Is it something that can be taught and learned or is it a condition? It is certainly possible to teach good citizenship but what you are teaching is how to be an ethical person within the state or condition of citizenship. Global or world citizen- 
ship is an implied state of absolute being whereas cosmopolitanism or international awareness can be taught and acquired over time. That is the real business of education in general and education abroad in particular. With that awareness, we will no longer blithely claim to bestow the grace of global citizenship on our students. What we will do (more reasonably) is empower them to learn something more of the world (or at least one part of it) in which they live. We will create specific and achievable learning goals that make sense to students and to our colleagues in academia.

In a more general sense, it would be good practice to be less effusive about outcomes in education abroad and to create objectives that are measurable and achievable. Stanley Fish, describing higher education in general, argues that exaggerated claims of "transformation" damage the credibility of the educational enterprise:

A good course may transform a student who knew little about the material in the beginning into a student who knows something about it at the end. That's about all the transformation you should or could count on. ${ }^{15}$

This is an important corrective and one that we should also apply to the idea of globalization. Using Fish's notion of "deflation"16, the objective in the following argument is to balance the idea of globalization (and thus the notion of a global citizen) against the counter realities of divergence and fragmentation.

\section{The Limits of Globalization}

Related to these issues is the fact that, in education abroad, we have used a very partial analysis of worldwide realities and have focused on the global dimension while ignoring or failing to recognize the existence of alternative dynamics operating in the contemporary context.

There is a tendency to assume that the rhetoric of globalization is matched by the reality. It is apparent that, for example, national cultures still shape the nature of particular educational systems and, thus, enforce difference and sustain diversity. An example from the European context may serve to illustrate this. The "European" idea began with an economic objective: to create a common market. Above all, this was a response to two cataclysmic world wars in the twentieth century in Europe. It was an attempt to create conditions in which conflict in the region would never again be seen to be in any national interest. From that point, the notion grew into a broader political and cultural concept of "Europe" conceived as a unified space with an identity and culture. As the nation state had to be invented in the nineteenth century, so this trans- 
national concept had consciously to be created roughly a hundred years later.

One perceived mechanism for the creation of Europe was, and is, educational mobility within the area. The true purpose of schemes like Erasmus and Socrates is, at heart, the invention of place: the creation of a generation that identifies themselves as Europeans rather than, for example, French or German. In that sense, the Erasmus program, like Garibaldi's march on Rome in 1867, was an attempt to bring a notion of place into reality. If this is a rather over-dramatic simile, it nevertheless places the process within a context of geographical myth-making. The notion of nation, as Italian and German history illustrates, is a relatively recent one in most parts of the world. Nations have had to seek to create their identities and their national myths against forces that simultaneously seek to pull them apart. If this is a major challenge within the country, it becomes a titanic problem within the region (let alone the globe) with regard to the invention of regional consciousness. Regions are constructed slowly and painfully. Pan Arab and Pan African movements have, we should remember, consistently failed to create anything resembling an identity that transcends the national (and sometimes even the tribal). If regionalism is, in many parts of the world, a distant aspiration, what is the state of global citizenship?

In Trust: The Social Virtues and the Creation of Prosperity, Francis Fukuyama makes a similar point in relation to economic systems and casts doubt upon the assumption that the economy is somehow "global":

... it is clear that there are sharp differences in the relative capabilities of states to plan and carry out industrial policies. These differences are shaped by culture, as well as by the nature of political institutions and historical circumstances of different countries. ${ }^{17}$

Fukuyama's definition of culture as "inherited ethical habit" ${ }^{18}$ is also helpful in that the notions of habit and inheritance locate culture nationally, tribally or regionally rather than in any global context. If his assertion that "culture shapes all aspects of human behaviour, including economic behaviour" 19 is accepted, it is apparent that the notion of a globalised world is one that requires significant review and refinement. This is not, of course, to suggest that there is no global dimension to national economies but rather to present the reality as more complex than "one-world" theories might suggest.

International education should not be dependent upon an unexamined myth of globalization. There are other general trends that are manifest, and there are those that specifically relate to international education. The broad assumption that the world is somehow globalised needs to be seen in a more conditional 
context. In education abroad, the implication is that we need to move towards specificity as we describe and define learning objectives.

\section{a) Some general observations}

Simple descriptions of national systems may well suggest some forms of similarity and convergence but these may also be illusory. An analogy with business illustrates this. A flow chart showing managerial structures and lines of communication might indicate broadly similar practices between two business enterprises. Such a description will, however, say little about how these enterprises really operate. Those of us who have tried, successfully or otherwise, to penetrate Japanese business or educational structures can easily testify to the issue of deep difference versus superficial similarity. The relationships between individuals, the manner of communication, the relationship between performance, pay and promotion, habitual practices and so on: these are factors governed by company culture which will, to some degree, reflect and embody national culture. In a similar way, national identity shapes the reality of a given educational system. The national dimension is, in this context, stronger than the global.

One could also cite the production and dissemination of ostensibly global products produced, for example, by Mercedes Benz and McDonald's. Mercedes Benz makes fine cars that are sold worldwide. In almost every case, however, the model needs to be modified to meet local needs and expectations. Regulations concerning emission levels vary. To export the car to Japan, South Africa or the UK the steering wheel has to be moved to the right. Expectations about the quality of interior furnishings vary from Germany (where certain models are seen by farmers, among others, as robust cars for working purposes) to the UK, for example, where the car is marketed as a luxury, status-symbol.

Even a product like a McDonald's burger is marketed differently within diverse national contexts. In France, it is possible to drink beer with your burger. In China or Japan, the burger represents access to a "Western fashionable" experience (as the queues outside McDonald's in Beijing signify) and the target audience are students and the young. In the UK, the market is decidedly younger still and McDonald's advertising is aimed at children and families. Thus, while the product is somewhat standard (not in fact universally so), the mode through which that product is perceived varies considerably. In some senses, therefore, the product is itself changed and reconstructed by its context.

The broad implication is that the outward signs of global similarity may mask considerable local distinction. That is also, clearly, the case in international higher education. 


\section{b) The higher education context}

There are, for example, very few examples of an "international" (let alone global) university, and even fewer of those, if any, are considered quality institutions. The vast majority of universities still offer national degrees, are recognised and accredited as national institutions and are funded through national mechanisms. There is a need to distinguish between universities with interests in international education (of which there are many) and international universities (of which there are very few).

The myth of globalization may also lead to an expectation of unhampered student mobility. The problems inherent in this context can be illustrated by reference to two theoretical models at either end of a spectrum of possibility. For the sake of shorthand they may be called the "liberal" and the "theological" model. It should be stressed that these are not specific institutions but extreme versions of certain characteristics that may be found within universities and schools in different national contexts.

The objectives and characteristics of a liberal school or university might be as follows: The curriculum demonstrates cultural diversity and the non-unitary notion of culture or history. This place debates and contests questions of national culture and identity. It may create conflicting notions of history (as in U.S.: Black, Gay, Native American, Women's perspectives) and oppositional versions of culture. The faculty express and encourage scepticism and inculcate values that permit disassociation from establishment values. Paradoxically, the State pays these faculty to perform (and perhaps, thus, to contain) this function. At the other end of this imaginary spectrum is the "theological" model. The term is broadly metaphorical. It signifies an institution that exists predominantly to enforce a given orthodoxy. It functions to some degree as a guardian of traditional values be they religious, political, moral or whatever. The primary objective is to transmit and defend "truth" not to challenge the notion of truth itself. In practice most educational systems and the institutions in them do not conform to these extreme models but exist somewhere between them.

A potential pitfall in terms of student mobility is, therefore, the assumption that educational systems across national boundaries fundamentally cohere. This fails, among other things, to recognise the variations shaped by "liberal" or "theological" tendencies. Failure to recognise difference or the bland assumption of shared purpose may lead to frustration and alienation unless understood and planned for within the development of international educational relations. The 
recognition of these diverse patterns is a pre-requisite for the creation of effective mechanisms for student mobility. The diversity is also, of itself, the true subject of international education.

At a grassroots level, the impact may be manifest in conflicting notions of what constitutes acceptable classroom behaviour. American students, for example, come to a host university overseas with an expectation that the objective of the class is to create a field of debate in which opinions are proposed and challenged. In some cultures, this expectation leads to behaviour that is both intimidating to other students within the class, and inappropriate to the teaching faculty. The reverse experience is also common: students who come to the US or the UK with the expectation that the professor is the source of unchallenged wisdom and the gatekeeper of cultural knowledge have difficult times in classes where the professor, instead of being the keeper of the holy grail of learning, performs the role of devil's advocate or, indeed, agitator.

Words matter. If we use words that suggest a coherent singularity, we create expectations that cannot be fulfilled. Global citizenship is just such a term. It minimizes the reality of difference and creates an illusion that such a thing as the unitary globe really exists. How can we raise the credibility of education abroad and convince sceptical colleagues of the value of this enterprise if we make such inflated and distorted claims?

\section{Conclusion: The Road to Nirvana?}

At the heart of this matter is the difference between a state of being and a process. This state of being is achieved, if at all, through learning and effort and it is, in many cases, elusive. Whatever we call this goal of enlightenment (Nirvana, Zion, global citizenship...), it is for all but the true believer a metaphorical place: a distant, dreamed location. Striving to reach this condition is the path of the moral or educated person (the good citizen?) who seeks improvement through learning and reflection, who aspires, in short to be a better citizen. That is the real business of education: creating analytical tools that empower students to take steps along a path. The end of that path is contested, dimly perceived and a matter of belief rather than evidence. Imagining the end of the path is, thus, a matter of ideological or religious faith (the business of the "priests" rather than the "professors").

That is why it will not do, in education abroad at least, to conflate notions of global/world citizenship with cosmopolitanism/international awareness. The first set of notions speak to an envisaged end point: some dreamed world that ignores the realities inherent in the limits of globalization not least sub-national 
conflict and poverty. The second set of notions relate to that which may be taught and learned. It does us a significant disservice to speak in the language of the prophets unless the goal is, indeed, to become a prophet. For most of us our goals are, advisably, more limited; as educators we aim to move students from relative ignorance towards relative understanding.

In general discourse the use of global citizenship is not damaging. It is merely an inexact term that suggests a set of aspirations indistinguishable from those that might define a good citizen. When related to education abroad, however, it creates unrealistic expectations, and claims more than the experience can reasonably be expected to deliver. Furthermore, it replaces an obligation to commit to the difficult process of learning with a wholly misleading and vague aspiration to reach some notion of a transformed state of grace. Global citizenship is, instead, a concept that needs to be explored, analysed, modified and contested within a coherent educational framework.

There is a danger that the rhetorical use of the term befuddles and confuses. The concept is ultimately elusive and, as Leo Rosten might suggest, you would be a little tsedreyt to use it too loosely:

Tsedreyt means mixed up, confused, wacky, demented.... A tsedreyeter is a man or boy who is all mixed up, a kook, a crank, a crackpot....A tsedreyte is a woman or girl nut, a crank, a kook, a lunatic.

Someone with a tsedreyeter kop is pleasantly pixilated...20

\section{End n o t e s}

${ }^{1}$ Leo Rosten, The New Joys of Yiddish (London: Arrow Books, 2003), pp.364-365.

${ }^{2}$ It is a simple enough matter to test this assertion by entering the terms study abroad + global citizenship into a web search. Over 220,000 hits on google result.

${ }^{3}$ April Carter, The Political Theory of Global Citizenship (London and New York: Routledge, 2001), p.74.

${ }^{4} 4$ th Inaugural Address, 20 January 1945

${ }^{5}$ http:www.oxfam.org.uk/education

${ }^{6}$ Taso G. Lagos, "Global Citizenship_-Towards a Definition," with the permission of the author. The article may be article found at the engagedcitizen.org website - http://depts.washington.edu/gcp/pdf/globalcitizenship.pdf

${ }^{7}$ Thomas Friedman, The World is Flat: The Globalized World in the Twenty-First Century (London: Penguin Books, 2006), p10. 
${ }^{8}$ Ibid., p.11.

$9 \mathrm{~J}$. Michael Adams and Angelo Carfagna, Coming of Age in a Globalized World: The Next Generation (Bloomfield: Kumarian Press, 2006), p 99

${ }^{10}$ Kofi Annan in an address to the World Economic Forum, January 29, 2001. ${ }^{11}$ Lagos op. cit.

${ }^{12}$ Ahmed I. Samatar, "Musings on Global Citizenship," Meditations on Global Citizenship, Macalester College Civic Forum 2007, v.1. Spring 2008, pp.7-8.

13 Adams, op.cit , p.10

${ }^{14}$ This point is enforced by Geoffrey Stokes in "Global Citizenship in Australia: Theory and Practice." He refers to " the pejorative use of 'cosmopolitanism' in Soviet and post-Soviet bloc countries to signify lack of patriotism and allegiance to international capital, or as a racist political code word for 'Jew"' in ed. Geoffrey Stokes, Roderic Pitty, Gary Smith, Global Citizens: Australian Activistsfor Change (Cambridge, Cambridge University Press, 2008), p.9.

${ }_{15}$ Stanley Fish, Save the World on Your Own Time (Oxford: Oxford University Press, 2008), p. 53.

${ }^{16}$ Ibid., p.53

${ }^{17}$ Francis Fukuyama, Trust: The Social Virtues and the Creation of Prosperity (London: Penguin Books, 1996), p. 15.

${ }^{18}$ Ibid., p. 34.

${ }^{19}$ Ibid., p. 18.

${ }^{20}$ Rosten op. cit. pp. 594-595 